\title{
A Rare Case of a Dual Diagnosis of Liver Disease
}

\author{
Ben David Warner ${ }^{\mathrm{a}, \mathrm{b}}$, Gary Mackenzie ${ }^{\mathrm{a}}$
}

\begin{abstract}
We present a rare presentation of a patient with combined Hereditary Hemochromatosis and Autoimmune Hepatitis who was an emergency presentation and who failed to improve until this dual diagnosis was realized and treatment for both was implemented. This case highlights the importance of the liver screen in clinical practice and serves as a learning point for doctors in training as well as specialists.
\end{abstract}

Keywords: Hemochromatosis; Liver; Hepatitis

\section{Introduction}

Chronic autoimmune hepatitis $(\mathrm{CAH})$ presents with a hepatitis with symptoms of jaundice, lethargy and arthralgia. It is defined histologically and by the presence of specific antibodies with high levels of immunoglobulin G. The treatment of this disease largely involves steroids and Azathioprine. Hereditary hemochromatosis $(\mathrm{HH})$ is an inherited disorder of iron transport through a mutation of the HFE gene leading to iron deposition in the liver and therefore cirrhosis. The disease progresses slowly over years with early detection and venesection preventing cirrhosis. The coexistence of 2 separate pathologies in patients presenting with abnormal liver function is not uncommon and failure to detect theses may result in patients being inappropriately treated.

\section{Case Report}

We present a case of a 57-year-old finance manager who pre-

\footnotetext{
Manuscript accepted for publication November 16, 2012

${ }^{a}$ East Surrey Hospital, Redhill, RH1 5RH, UK

${ }^{\mathrm{b}}$ Corresponding author: Ben David Warner, East Surrey Hospital,

Redhill, RH1 5RH, UK. Email: b.warner@uclmail.net

doi: http://dx.doi.org/10.4021/jmc972w
}

sented to his GP with a month's history of weight loss and right upper quadrant pain. More recently his stools had become pale and his urine darker and his wife had noticed that he was looking yellow.

His past medical history included diverticular disease and removal of varicose veins on his right leg. He had been to Egypt 4 months previously where he had had an episode of diarrhoea but this had resolved with antibiotics. He was taking only Omeprazole for dyspepsia. There was no family history of liver disease. He drunk around 5 units of alcohol per week and did not smoke.

On examination, he appeared well but had some mild right upper quadrant tenderness with no stigmata of chronic liver disease.

His blood tests showed a hepatitic picture with a bilirubin of $48 \mu \mathrm{mol} / \mathrm{L}$ (NR 2 - 17), an alanine transferase (ALT) of $619 \mathrm{U} / \mathrm{L}(4-21)$, an alkaline phosphatase (ALP) of 164 $\mathrm{U} / \mathrm{L}(35$ - 104), an albumin of $34 \mathrm{~g} / \mathrm{L}(34$ - 48) and an INR of 1.8 .

He was referred to a Consultant Gastroenterologist at our District General Hospital who requested the relevant liver screen including an ultrasound of his liver which was normal. His liver screen returned as showing the presence of smooth muscle antibodies (SMA) at a titre of 1:640 suggesting the cause to be a chronic autoimmune hepatitis (CAH).

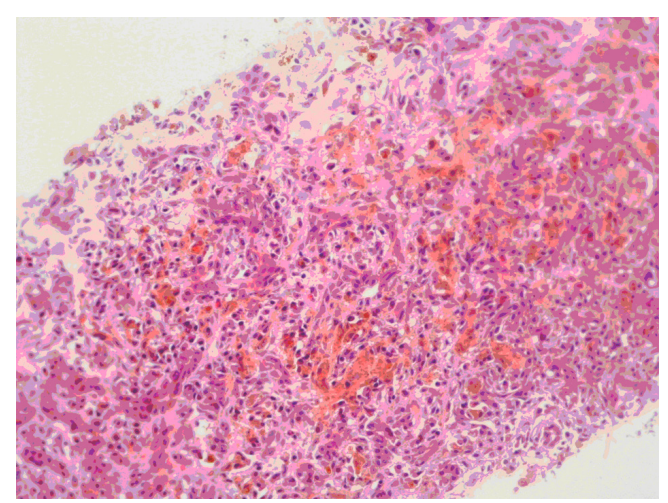

Figure 1. Showing areas of severe sideronecrosis and plasmacytosis with marked hepatocyte loss in keeping with an acute hepatitis. 
He had a liver biopsy to confirm the diagnosis and was commenced on a reducing dose of steroids but his symptoms and liver function failed to show any improvement. Whilst being on steroids the remainder of his iron studies returned as showing a very high ferritin of $8,190 \mathrm{U} / \mathrm{L}$ with an iron saturation of $94 \%$ and an iron level of $34 \mu \mathrm{g} / \mathrm{L}$. His liver biopsy returned showing acute hepatocyte damage due to sideronecrosis but with no fibrosis (Fig. 1). Genetic studies confirmed him positive for the HFE gene and confirmed a dual pathology underlying his hepatitis which was a mixture of hemochromatosis and chronic autoimmune hepatitis.

He was continued on a reducing dose of steroids and later commenced on Azathioprine whilst also having regular venesections, 6 months later his liver function had returned to normal and symptomatically he was much improved.

\section{Discussion}

$\mathrm{HH}$ is a commonly inherited disorder of iron metabolism affecting between 1 in 200 and 1 in 400 people. The HFE gene responsible is recessively inherited and alters the transferrin receptor to increase iron absorption with subsequent tissue iron deposition. The most common form is homozygosity for the $\mathrm{C} 282 \mathrm{Y}$ mutation but another less common from involves the H63D mutation. It is important to separate $\mathrm{HH}$ from other causes of chronic liver disease with iron overload and this is done by identification of the HFE gene or through biopsy. Approximately $50 \%$ of patients with alcoholic liver disease, non-alcoholic steatohepatitis (NASH) and chronic viral hepatitis will have serum abnormalities of iron metabolism involving increased ferritin or occasionally a raised transferrin saturation as well [1]. Hepatic iron levels are typically normal in these patients as opposed to $\mathrm{HH}$ where they are very raised. There is a strong argument for generalised population screening for $\mathrm{HH}$ as early identification and treatment of the disease can prevent tissue damage.

$\mathrm{CAH}$ is defined histologically by the presence of piecemeal necrosis and plasma infiltration of the portal tracts persisting for greater than 6 months. Infections such as hepatitis $\mathrm{B}$ and $\mathrm{C}$ are recognised aetiological agents but $\mathrm{CAH}$ can arise with other liver diseases as well as a reaction to drugs [2]. However, a diagnosis of autoimmune hepatitis is made only after excluding these aetiological agents as well as through the detection of specific antibodies and typically hypergammaglobulinaemia. Classical and non-classical subgroups have been described with the detection of smooth muscle antibodies and anti-liver/kidney microsomal antibodies respectively. As hepatitis $\mathrm{C}$ is implicated as a trigger for $\mathrm{CAH}$, screening of the virus in patients with $\mathrm{CAH}$ is important with regard to steroid treatment.

The coexistence of liver pathologies is underreported and can remain undetected in patients who present to hospital with abnormal liver function. Certain conditions are com- monly seen in association with one another such as alcohol and hepatitis $\mathrm{C}$, but $\mathrm{HH}$ found in a patient with $\mathrm{CAH}$ is not found in the literature. $\mathrm{HH}$ has been found with hepatitis $\mathrm{C}$ and NASH [3] but remains either rare in clinical practice or under-detected and underreported.

Mendenhall et al 1991 [4] found that 27\% of 350 patients with alcoholic liver disease were anti-HCV-positive. Combined alcoholic liver disease with hepatitis $\mathrm{C}$ has been proposed as a reason why only some patients with significant alcohol intake actually develop alcoholic liver disease. The presence of both may be environmental although only $87 \%$ of alcohol abusers who test positive for HCV antibodies admit to intravenous drug abuse. An additional reason might be that portal and lobular inflammation alters the pathogenesis of the hepatitis $\mathrm{C}$ promoting its chronicity through altered leukocyte action and relative immunosupression. Nakano et al 1993 [5] showed that patients with cirrhosis from alcohol and hepatitis $\mathrm{C}$ showed increased fibrosis than patients with chronic hepatitis $\mathrm{C}$ alone. The study also showed a decline in viral load with abstinence. Nalpas et al [6] suggest that coexistent liver pathologies such as alcohol and either hepatitis B or C play a synergistic role in the development of liver injury.

A study in Israel of 496 alcoholics found that $4.8 \%$ were hepatitis B positive and $7.6 \%$ were hepatitis $\mathrm{C}$ positive [7].

Studies of patients with combined hepatitis $\mathrm{C}$ and $\mathrm{HH}$ (especially the $\mathrm{C} 282 \mathrm{Y}$ mutation) have also shown increased fibrosis and cirrhosis [3]. Likewise coexistent NASH and $\mathrm{HH}$ have been reported and demonstrate earlier cirrhosis in these patients.

A case of fulminant hepatic failure resulting from coexistent Wilson's disease with Hepatitis E was reported by Sallie et al 1994 [8] involving a 6-year-old girl who developed jaundice a fortnight after her return from India. Copper studies were consistent with Wilson's Disease and PCR on liver serum after liver transplant were positive for HEV RNA.

The importance of detecting coexistent disease is again demonstrated by the management of alcoholic hepatitis where cases have been reported of fulminant hepatitis resulting from withdrawal of steroids [9]. Also, the predisposition to hepatocellular carcinoma is much greater with cirrhosis from both alcohol and hepatitis $\mathrm{C}[10,11]$. As previously stated hepatitis $\mathrm{C}$ is known to be a trigger for $\mathrm{CAH}$ and therefore detection of the virus has an important influence on treatment.

This case report highlights the importance of detecting coexistent pathologies in clinical practice. It is important that a full liver screen is done in investigating patients with abnormal liver function tests. Detection of coexistent pathologies not only influences treatment but also affects prognosis. HH genotype itself is relatively common as a disease in the population but probably remains undetected and has uncertain disease penetrance. There is an ongoing debate regarding population screening but it is essential to investigate 
patients for HH genotype who have liver disease even if an alternative cause has already been found.

\section{References}

1. Di Bisceglie AM, Axiotis CA, Hoofnagle JH, Bacon BR. Measurements of iron status in patients with chronic hepatitis. Gastroenterology. 1992;102(6):2108-2113.

2. Johnson PJ. Autoimmune chronic active hepatitis. Hong Kong Med J. 1997;3(1):43-49.

3. Bacon BR. Hemochromatosis: diagnosis and management. Gastroenterology. 2001;120(3):718-725.

4. Mendenhall CL, Seeff L, Diehl AM, Ghosn SJ, French SW, Gartside PS, Rouster SD, et al. Antibodies to hepatitis $\mathrm{B}$ virus and hepatitis $\mathrm{C}$ virus in alcoholic hepatitis and cirrhosis: their prevalence and clinical relevance. The VA Cooperative Study Group (No. 119). Hepatology. 1991;14(4 Pt 1):581-589.

5. Nakano M, Maruyama K, Okuyama K, Takahashi H, Yokoyama K, Takagi S, Shiraki H, et al. The characteristics of alcoholics with $\mathrm{HCV}$ infection: histopathologic comparison with alcoholics without HCV infection and chronic type C hepatitis. Alcohol Alcohol Suppl.
1993;1B:35-40.

6. Nalpas B, Thiers V, Pol S, Driss F, Thepot V, Berthelot P, Brechot C. Hepatitis C viremia and anti-HCV antibodies in alcoholics. J Hepatol. 1992;14(2-3):381-384.

7. Srugo I, Shinar E, Bar-Shany S, Amos L. Hepatitis B and $\mathrm{C}$ markers among alcoholics in Israel: high incidence of HCV infection. Eur J Epidemiol. 1998;14(4):333-337.

8. Sallie R, Chiyende J, Tan KC, Bradley D, Portmann B, Williams R, Mowat AP, et al. Fulminant hepatic failure resulting from coexistent Wilson's disease and hepatitis E. Gut. 1994;35(6):849-853.

9. Fan FS, Tzeng CH, Hsiao KI, Hu ST, Liu WT, Chen PM. Withdrawal of immunosuppressive therapy in allogeneic bone marrow transplantation reactivates chronic viral hepatitis C. Bone Marrow Transplant. 1991;8(5):417420.

10. Miyakawa H, Sato C, Izumi N, Tazawa J, Ebata A, Hattori $\mathrm{K}$, Sakai H, et al. Hepatitis C virus infection in alcoholic liver cirrhosis in Japan: its contribution to the development of hepatocellular carcinoma. Alcohol Alcohol Suppl. 1993;1 A:85-90.

11. Grellier LF, Dusheiko GM. The role of hepatitis C virus in alcoholic liver disease. Alcohol Alcohol. 1997;32(2):103-111. 